\title{
Effect of educational nursing program on quality of life for patients with type II diabetes mellitus at Assiut University Hospital
}

\author{
Neama Mamdouh Mostafa*1, Ghada Hassan Ahmed ${ }^{1}$, Walaa Anwar ${ }^{2}$ \\ ${ }^{1}$ Medical-Surgical Nursing Dept, Faculty of Nursing, Assiut University, Assiut, Egypt \\ ${ }^{2}$ Internal Medicine Dept, Faculty of Medicine, Assiut University, Assiut, Egypt
}

Received: March 6, 2018

DOI: $10.5430 / j n e p . v 8 n 11 \mathrm{p} 61$

\author{
Accepted: May 11, 2018 \\ Online Published: June 25, 2018 \\ URL: https://doi.org/10.5430/jnep.v8n11p61
}

\begin{abstract}
Background: Diabetes mellitus constantly changes a patient's life. Patient's self care, consisting of daily insulin injections or oral anti-diabetic agents, self monitoring of blood glucose and diabetic diet has an impact on QOL. The aim of the present study was to assess quality of life for patients with type II diabetes mellitus, to develop and implement an educational nursing program for patients with type II diabetes mellitus, to evaluate the effect of applying the educational nursing program on quality of life for patients with type II diabetes mellitus pre and after two months from application of educational program.

Methods: The study was conducted in the internal medicine department, internal medicine and diabetes clinic at University Hospital (Assiut-Egypt). Sixty adult patients were divided randomly equally into two groups (study group and control group) thirty for each group. The following tools were utilized for data collection: first tool "Structured patient interview questionnaire sheet"; it included two parts (socio-demographic characteristic and medical data), second tool "World Health Organization Quality of life (WHOQOL-WHO) scale".

Results: In the control group $40 \%$ of diabetic patients had good quality of life score while in the study group $100 \%$ had good quality of life after application of the educational program.

Conclusions: The results of the present study concluded that: according to the control group, there was no statistically significant difference pre and post program in all domains of quality of life scale. According to the study group there was a highly significant effect of educational program on promotion of quality of life in physical, psychological, and social domains scale. Recommendations: Providing a written educational nursing program is of great importance for the patients.
\end{abstract}

Key Words: Type II Diabetes, Educational program, Quality of life

\section{INTRODUCTION}

Diabetes is considered one of the common health problems over the world whose complications not only have severe effects on quality of life (QOL) but also lead to disabilities and increased mortality rate among patients with diabetes. ${ }^{[1]}$ Complications and chronic adverse effects of diabetes have large impact on the QOL of patients with diabetes and also affect patients' economic status, their families and the society they live in. The Clinical Guide for Managing T2DM strongly emphasized the improvement of QOL in patients with T2DM. ${ }^{[2]}$ The findings of studies over the past two decades have also shown that the main goal of diabetes treatment is not to deal with the physical symptoms of such a

\footnotetext{
*Correspondence: Neama Mamdouh Mostafa; Email: neama.mostafa45@yahoo.com; Address: Medical-Surgical Nursing Dept, Faculty of Nursing, Assiut University, Assiut, Egypt.
} 
disease but to improve QOL. QOL is a very important health outcome as well as the goal of all health-related interventions. ${ }^{[3]}$

The WHO defined QOL as individuals' perceptions of their current situations regarding systematic and cultural values in which they live in and the relationships between these perceptions and goals, expectations, standards, and priorities important fore them. ${ }^{[4]}$

One of the low cost strategies used in the training of individuals with DM for self-management is health education. As it improves the acquiring of knowledge, encouraging the attitude of adherence beneficial to the disease and treatment, metabolic control, reduction of acute and chronic complications and, therefore, improve QOL. The nursing care goal is to achieve the improvement in QOL of individuals and health education programs can positively add value to the acquisition of knowledge and the adoption of positive attitude towards the disease and treatment, reflecting, therefore QOL. ${ }^{[5]}$

As education is a supportive and dynamic process, it has a very special role in awareness, changing attitudes, changing life style, building confidence and it also can contribute to improving the quality of life. A very important role of nurses is education of diabetic patients and their families on their diet, blood glucose levels self-monitoring, adherence to prescribed medications, exercise, self-care, follow-up and ongoing management of the disease. ${ }^{[6]}$

Diabetes educational program is essential in preventing complications especially in adult people suffering from diabetes such as retinopathy which is the leading cause of blindness, kidneys (nephropathy) as 10\%-20\% of patients with diabetes die from renal diseases, nerves (neuropathy) which affect up to $50 \%$ of patients with diabetes. ${ }^{[7,8]}$

Self-management education is recommended as a basic component of diabetes management in clinical practice. The National Standards for Diabetes Self-Management Education and Support define diabetes self-management education as a collaborative and ongoing process intended to facilitate the development of knowledge, skills, and abilities that are required for successful self-management of diabetes. ${ }^{[9,10]}$

\subsection{Significance of the study}

As the rates of diabetes are increasingly growing and the devastating effects of it on all life dimensions in patients and it necessitate the conduction of research on QOL of these patients. 480 patients had diabetes in internal medicine department and out-patient at Assiut university hospital in 2017, so this study was conducted to investigate the effects of an educational nursing program on QOL in patients with

\section{T2DM.}

\subsection{Aims of the study}

(1) To assess quality of life for patients with type II diabetes mellitus.

(2) To develop and implement an educational nursing program for patients with type II diabetes mellitus.

(3) To evaluate the effect of applying the educational nursing program on quality of life for patients with type II diabetes mellitus pre and after two months from application of educational program.

\subsection{Research hypothesis}

Quality of life of the study group patients will be better after application of the educational nursing program than those in the control group.

\section{Patients and method}

\subsection{Research design}

Quasi experimental design was utilized to fulfill the aim of this study.

\subsection{Setting}

The study was conducted in the internal medicine department, internal medicine and diabetes clinic at Assiut university hospital.

\subsection{Subjects}

Sixty adult patients divided randomly equally into two groups (study group and control group) thirty for each group.

\subsection{Randomization process}

The researchers were visiting the clinic twice a week; Mondays and Thursdays, those who visit the clinic on Monday were included as a study subject and those on Thursday were included in the control group

\subsection{Inclusive criteria}

Aged between 20-65 years. Male and female patients regardless their educational level.

\subsection{Tools}

Tool I: Structured patient interview questionnaire sheet. It included two parts.

Part 1: Socio-demographic characteristic includes patient's age, gender, marital status, educational level, income residence, and occupation.

Part 2: Medical data includes past medical history, present medical history, previous admission/month, presence of other chronic diseases, regularity of treatment, family history, duration of illness, and blood sugar. 
Tool II: World Health Organization Quality of life (WHOQOL-WHO) scale. It was used to assess quality of life for patients with diabetes mellitus. The tool contain 54 questions distributes on five broad domains of QOL. Within each domain, there are several sub domains of QOL. The five main domains and their sub domains are:

(1) Physical health domain including: activities of daily living, pain and discomfort, power and fatigue, sleep and rest, ability to work, mobility and dependence on medication.

(2) Psychological domain including: negative feelings, positive feelings and self esteem.

(3) Social domain including: personal beliefs, personal relationships, social support, medical and social services.

(4) Environmental domain including: environmental factor (pollution \& noise), and environmental safety and security).

(5) General quality of life.

\subsection{Scoring system}

Scoring these variables, was on 3-point scale, which ranged from never $(1)=$ low quality of life, moderate $(2)=$ moderate quality of life, much (3) = high quality of life.

Each facet comprised 3 questions. The highest score for every facet was 1-9. The total score was evaluated as follows: low 1-3, moderate 4-6, and high 7-9.

\subsection{Educational nursing program}

It was developed by the researchers based on patient's assessment, literature review, and research experience. It was formulated and introduced to the patients in the form of sessions. It was written in Arabic using simple language with illustration. It consisted of the following items: definition of diabetes mellitus, types of diabetes mellitus, causes of diabetes mellitus, signs and symptoms of diabetes mellitus, treatment of diabetes mellitus, nursing management of diabetes mellitus, acute and chronic complications of diabetes mellitus.

\subsection{Procedure}

An official permission to conduct the proposed study was obtained from director of the university hospital and the head of medical department at Assiut University Hospital. At initial interview, the researcher introduced herself to initiate line of communication, and explained the nature and purpose of the study. The tools were tested for content validity by 5 experts ( 2 academic internal Medicine staff and 3 nursing staff from faculty of Nursing) at Assiut University who reviewed the tools for clarity, relevance, comprehensiveness and understanding. Minor modifications were required and correction was carried out accordingly. Then the final form of the tool was designed and tested for reliability by using internal consistency for the tools measured using Cronbach test, the tools proved to be reliable (0.73).

A pilot study was conducted on $10 \%$ of the sample to test feasibility, objectivity, validity and applicability of the study tools. Patient's agreement for voluntary participation was obtained after the purpose and nature of the study were explained. The researcher filled in tools of the study from the patient using the structured patient interview questionnaire. The data were collected from May 2017 to October 2017. The tools were applied on 60 patients through an interviewing questionnaire. Before that the researcher introduced herself to each patient, explained the purpose of the study and the reason for interviewing. First collection of sociodemographic and medical data was done. The total time for collection the data was about 30 minutes for every patient. For the control group, after taking the patient oral agreement for voluntary participation in the study, the researcher then filled structured patient interview questionnaire, WHOQOL assessment scale. The control group received the routine resident oral instructions. The researcher met the patient in internal medicine and diabetes outpatient clinic after two months for re-evaluating the patient's condition. For the study group, after filling the structured patient interview questionnaire, WHOQOL assessment scale. The researcher explained to the patient the educational program during hospital stay and evaluated patients after two months in internal medicine and diabetes clinic.

The educational program was administered to the patients in three sessions; the duration of each session was about one hour three times weekly, including 15 minutes for discussion and feedback by using lecture for knowledge and videos for practice such as subcutaneous injection and insulin pump. Patients divided small groups according to number of cases of diabetes weekly. First session: The researcher started by introducing herself to the patients telling them aim of the meeting, orient patients regarding the educational program. Contents of this session include: definition of diabetes mellitus, causes of diabetes mellitus and types of diabetes mellitus. Second session: summary about what has been discussed in a previous session, objectives of the new session, and contents of this session includes: signs and symptoms of diabetes mellitus, treatment of diabetes mellitus. and the session ended by a summary of its content and feedback from the patients. Many patients were cooperative and interested in a given topic and asked to continue. Third session: summary about what has been discussed in a previous session, objectives of the new session, and contents of this session include: com- 
plications of diabetes mellitus, nursing management of type

II diabetes mellitus. The session ended by a summary of its content and feedback from the patients through discussion and asking questions. After ending the sessions, every patient was given a copy of educational program at home.

Evaluation was carried out pre and after two months through introducing tool (I) and tool (II) for all the studied sample "both control and study group" to distinguish between control and study group after application of the educational nursing program and between the initial assessment of the studied group and their assessment after two months from application of the educational nursing program.

\subsection{Ethical considerations}

The study was approved by the faculty of nursing - Assiut University ethics committee, a written consent was obtained from patients to participate in the study after explaining the aim and nature of the study to them. Data confidentiality and anonymity was assured and patients were informed that their participation in the study is voluntary and will not affect the care they receive if they decided to withdraw from the study.

\subsection{Difficulties of the study}

Patient lived in rural areas suffered from transportation and financial problems.

\subsection{Statistical design}

The data were tested for normality using the AndersonDarling test and for homogeneity variances prior to further statistical analysis. Categorical variables were described by number and percent $(\mathrm{N}, \%)$, where continuous variables described by mean and standard deviation (Mean, SD). Chisquare test and fisher exact test used to compare between categorical variables where comparing between continuous variables was done by $t$-test and ANOVA, Pearson and Spearman correlation coefficients, a two-tailed $p<.05$ was considered statistically significant. All analyses were performed with the IBM SPSS 20.0 software.

\section{Results}

Table 1 shows that $43.3 \%$ of the study group their age was 40 50 years while $36.7 \%$ of the control group was $40-50$ years. Regarding sex it was found that the highest percentages in both groups (study and control) were female. Regarding marital status it was found that the highest percentages in both groups (study and control) were married. Regarding education it was found that $40 \%$ of the study group were secondary educated while $43.3 \%$ of the control group were not educated. Regarding occupation it was found that the highest percentages in both groups (study and control) were housewives.

Table 1. Distribution of the studied sample (study and control groups) regarding sociodemographic characteristics $(\mathrm{n}=60)$

\begin{tabular}{|c|c|c|c|c|c|}
\hline \multirow{2}{*}{ Characteristics } & \multicolumn{2}{|c|}{ Study $(\mathrm{n}=30)$} & \multicolumn{2}{|c|}{ Control $(n=30)$} & \multirow{2}{*}{$p$ value } \\
\hline & N. & $\%$ & N. & $\%$ & \\
\hline Age & \multicolumn{2}{|l|}{$46.38 \pm 9.62$} & \multicolumn{2}{|l|}{$50.67 \pm 8.81$} & .113 \\
\hline$<40$ years & 7 & 23.3 & 5 & 16.7 & \\
\hline $40-50$ years & 13 & 43.3 & 11 & 36.7 & \\
\hline $51-60$ years & 9 & 30.0 & 11 & 36.7 & .637 \\
\hline$>60$ years & 1 & 3.3 & 3 & 10.0 & \\
\hline \multicolumn{6}{|l|}{ Sex } \\
\hline Male & 12 & 40.0 & 6 & 20.0 & \multirow{2}{*}{.091} \\
\hline Female & 18 & 60.0 & 24 & 80.0 & \\
\hline \multicolumn{6}{|l|}{ Marital status } \\
\hline Single & 1 & 3.3 & 1 & 3.3 & \multirow{4}{*}{.558} \\
\hline Married & 29 & 96.7 & 27 & 90.0 & \\
\hline Divorced & 0 & 0.0 & 1 & 3.3 & \\
\hline Widow & 0 & 0.0 & 1 & 3.3 & \\
\hline \multicolumn{6}{|l|}{ Educational level } \\
\hline Preparatory School & 3 & 10.0 & 8 & 26.7 & \multirow{4}{*}{.099} \\
\hline Secondary School & 12 & 40.0 & 5 & 16.7 & \\
\hline University & 6 & 20.0 & 4 & 13.3 & \\
\hline Not educated & 9 & 30.0 & 13 & 43.3 & \\
\hline \multicolumn{6}{|l|}{ Occupation } \\
\hline Employer & 10 & 33.3 & 6 & 20.0 & \multirow{4}{*}{.388} \\
\hline House Wife & 19 & 63.3 & 20 & 66.7 & \\
\hline Retired & 0 & 0.0 & 1 & 3.3 & \\
\hline Dose not work & 1 & 3.3 & 3 & 10.0 & \\
\hline \multicolumn{6}{|l|}{ Residence } \\
\hline Urban & 24 & 80.0 & 12 & 40.0 & \multirow{2}{*}{$.002^{* *}$} \\
\hline Rural & 6 & 20.0 & 18 & 60.0 & \\
\hline
\end{tabular}


Table 2 shows that regarding o previous admission to the hospital, the highest percentages in both groups (study and control) were not admitted to the hospital previously. As regarding regularity of medication, the highest percentages in both groups (study and control) maintained the regularity of medication. Regarding duration of the disease; it was found that $40 \%$ of the study group was between $5-10$ years while in the control group were less than 5 years. Regarding family history the highest percentages in both groups (study and control) had positive family history. Neuropathy represented the highest percent in both groups. There was no statistically difference between both groups as regard to medical data.

Table 3 shows that in the control group, $40 \%$ of diabetic patient had good quality of life score while in the study group $100 \%$ had good quality of life after application of the educational program. There was no statistically significant difference pre and post program in the control group while in the study group there was highly significant difference pre and post program.

Table 2. Distribution of the studied sample (both study and control groups) regarding to medical data

\begin{tabular}{|c|c|c|c|c|c|}
\hline \multirow{2}{*}{ Medical data } & \multicolumn{2}{|c|}{ Study $(n=30)$} & \multicolumn{2}{|c|}{ Control $(n=30)$} & \multirow{2}{*}{$p$ value } \\
\hline & $\mathbf{N}$. & $\%$ & $\mathbf{N}$. & $\%$ & \\
\hline \multicolumn{6}{|l|}{ Previous admission } \\
\hline Yes & 5 & 16.7 & 4 & 13.3 & \multirow{2}{*}{.718} \\
\hline No & 25 & 83.3 & 26 & 86.7 & \\
\hline \multicolumn{6}{|c|}{ Regularity of medication } \\
\hline Yes & 23 & 76.7 & 27 & 90.0 & \multirow{2}{*}{.166} \\
\hline No & 7 & 23.3 & 3 & 10.0 & \\
\hline \multicolumn{6}{|l|}{ Duration of disease } \\
\hline$<5$ years & 12 & 40.0 & 12 & 40.0 & \multirow{3}{*}{.792} \\
\hline 5-10 years & 12 & 40.0 & 10 & 33.3 & \\
\hline$>10$ years & 6 & 20.0 & 8 & 26.7 & \\
\hline \multicolumn{6}{|c|}{ Medical family history } \\
\hline Yes & 15 & 50.0 & 22 & 73.3 & \multirow{2}{*}{.063} \\
\hline No & 15 & 50.0 & 8 & 26.7 & \\
\hline Blood sugar value & 266 & & 231 & & .060 \\
\hline \multicolumn{6}{|l|}{ Type of medications } \\
\hline Oral & 20 & 66.7 & 13 & 43.3 & \multirow{2}{*}{.069} \\
\hline Insulin & 10 & 33.3 & 17 & 56.7 & \\
\hline \multicolumn{6}{|c|}{ Presence of other chronic diseases? } \\
\hline Yes & 16 & 53.3 & 16 & 53.3 & \multirow[t]{2}{*}{1.000} \\
\hline No & 14 & 46.7 & 14 & 46.7 & \\
\hline \multicolumn{6}{|c|}{ Presence of any complications for DM? } \\
\hline Yes & 19 & 63 & 17 & 56.7 & \multirow[t]{2}{*}{.598} \\
\hline No & 11 & 37 & 13 & 43.3 & \\
\hline \multicolumn{6}{|c|}{ Complication of DM Type of } \\
\hline Neuropathy & 17 & 56.7 & 10 & 33.3 & .069 \\
\hline Eye complication & 2 & 6.7 & 1 & 3.3 & .554 \\
\hline Diabetic Foot & 0 & 0.0 & 6 & 20.0 & $.010^{*}$ \\
\hline
\end{tabular}

Table 3. Total score of the quality of life for both group patients' pre and post program

\begin{tabular}{|c|c|c|c|c|c|c|c|c|c|c|}
\hline \multirow{3}{*}{ Total quality of life } & \multicolumn{5}{|c|}{ control group $(n=30)$} & \multicolumn{5}{|c|}{ Study group $(n=30)$} \\
\hline & \multicolumn{2}{|c|}{ Pre } & \multicolumn{2}{|c|}{ Post } & \multirow{2}{*}{$p$ value } & \multicolumn{2}{|c|}{ Pre } & \multicolumn{2}{|c|}{ Post } & \multirow{2}{*}{$p$ value } \\
\hline & N. & $\%$ & $\mathbf{N}$. & $\%$ & & $\mathbf{N}$. & $\%$ & $\mathbf{N}$. & $\%$ & \\
\hline Poor & 3 & 10.0 & 3 & 10.0 & & 2 & 6.7 & 0 & 0.0 & \\
\hline Moderate & 14 & 46.7 & 15 & 50.0 & .963 & 11 & 36.7 & 0 & 0.0 & $<.001^{* *}$ \\
\hline Good & 13 & 43.3 & 12 & 40.0 & & 17 & 56.7 & 30 & 100.0 & \\
\hline Mean \pm SD & \multicolumn{2}{|c|}{$113.43 \pm 12.41$} & \multicolumn{2}{|c|}{$113.23 \pm 17.71$} & .949 & \multicolumn{2}{|c|}{$115.40 \pm 12.07$} & \multicolumn{2}{|c|}{$135.50 \pm 5.40$} & $<.001 * *$ \\
\hline
\end{tabular}




\section{Discussion}

Regarding duration of disease it was found that two fifths $40 \%$ of the study group was between 5-10 years while in the control group was less than 5 years. This study finding was supported by Haas and Maryniuk ${ }^{[11]}$ who stated that the presence of diabetes mellitus lower all domains of QOL.

As regard to family history the highest percentages in both groups (study and control) had positive family history. This study comes with Al Hayek et al. ${ }^{[12]}$ who reported that a positive familial threat of diabetes had recognized seventy three percent of all respondents with diabetes and successfully had anticipated diabetes in $21.5 \%$ of respondents.

Regarding presence of any complications, it was found that the highest percentages in both groups had complications. Neuropathy represented the highest percent in both groups. This study result agree with Susan et al. ${ }^{[13]}$ who illustrated that DM complications accounted for an expanded morbidity, incapacity, and mortality and represent a threat for the economies of all nations, specially the developing ones.

This study results revealed that in the control group $40 \%$ of diabetic patients had good quality of life score while in the study group $100 \%$ had good quality of life after application of the educational program. There was no statistically significant difference pre and post program in the control group while in the study group there was highly significant difference pre and post program. This study result in agreement with Fahad et al. ${ }^{[14]}$ who reported that diabetes has an impact on various fitness outcomes which include QOL, diabetes impaired all dimensions of health except intellectual health and ache and illustrated that less than one fourth of diabetic patients had proper high-quality of life (21.3\%), and maximum diabetic patients (seventy eight, 78\%) had bad exceptional of existence.
This study result is also supported by Aliasghar et al. ${ }^{[15]}$ who illustrated that six studies, which examined the effect of diabetes on HRQoL (health related quality of life), compared HRQoL in people with and without diabetes and reported negative outcomes of type 2 diabetes on HRQoL.

This study agreed with Sima et al. ${ }^{[16]}$ who demonstrated in their study entitled "Effect of Educational Program on Quality of Life of Patients with Heart Failure" that there were significant differences in QOL in experimental group compared to control group. In addition, compared to baseline, there were statistically significant differences in QOL for participants in the experimental group, so that they had significantly improved QOL. However, no significant differences were observed in the control group. Considering the similarity of participants in the two groups, the improvement of QOL in intervention group could be related to educational program.

\section{Conclusion}

The results of the present study concluded that: according to the control group, there was no statistically significant difference pre and post program in all domains of quality of life scale. According to the study group there was a highly significant effect of educational program on promotion of quality of life in physical, psychological, and social domains scale.

\section{Recommendations}

Providing a written educational program is of great importance for the patients.

\section{CONFLiCTS OF InTEREST Disclosure}

The authors declare that there is no conflict of interest.

\section{REFERENCES}

[1] Moayeri A, Mohamadpour M, Mousavi SF. Fracture risk in patients with type 2 diabetes mellitus and possible risk factors: a systematic review and metaanalysis. Ther Clin Risk Manag. 2017; 11: 455-468 PMid:28442913 https://doi .org/10.2147/TCRM. S131945

[2] Sobhani S, Asayesh H, Sharifi F. Prevalence of diabetic peripheral neuropathy in Iran: a systematic review and meta-analysis. J Diabetes Metab Disord. 2014; 13: 97-105. PMid:25364702 https: //doi.org/10.1186/s40200-014-0097-y

[3] Chen CM, Chang YM. The experiences of diabetics on selfmonitoring of blood glucose: a qualitative metasynthesis. J Clin Nurs. 2015; 24(5-6): 614-26. PMid:25258005 https ://doi .org/ $10.1111 /$ jocn. 12691

[4] Cloete EA. "Electronic Education System Model." Department of Computer Science and Information Systems in South Africa. 2015.
[5] Asmamaw A, Asres G, Negese D, et al. Knowledge and attitude about diabetes mellitus and its associated factors among people in Debre Tabor town, Northwest Ethiopia: cross sectional study. Science Journal of Public Health. 2015; 3(2): 199-209. https: //doi.org/10.11648/j.sjph.20150302.17

[6] Lewis SL, Dirksen SR, Heitkemper MM, et al. Medical Surgical Nursing, Assessment and management of clinical problems. 2nd ed. Diabetes mellitus, Elsevier company; 2015. 1130-1135 p.

[7] Alkaissi A. Complications of diabetes mellitus. 2013. Available from: http://www.najah.edu/file/Essays/english/Aidah

[8] WHO Media Centre. Facts Sheets. 2012.

[9] American Diabetes Association. Standards of medical care in diabetes. Diabetes Care. 2011; 34(Suppl 1): S11-61. PMid:21193625

[10] Haas LM, Maryniuk JB. National standards for diabetes self management education and support. Diabetes Educ. 2012; 38: 619-629. 
PMid:22996411 https://doi.org/10.1177/01457217124559 97

[11] Al Hayek AA, Robert AA, Al Saeed A. Factors Associated with Health-Related Quality of Life among Saudi Patients with Type 2 Diabetes Mellitus: A Cross-Sectional Survey. Diabetes \& Metabolism Journal. 2014; 38(3): 220-229. PMid:25003076 https ://doi .or $\mathrm{g} / 10.4093 / \mathrm{dmj} \cdot 2014.38 \cdot 3.220$

[12] Susan H, Paula WY, Nadeem Q, et al. Diabetes symptoms type 1 and type 2. 2016.

[13] Papatheodorou K, Papanas N, Banach M, et al. Complications of
Diabetes 2016. Journal of Diabetes Research. 2016.

[14] Fahad S, Al-Shehri. Quality of Life among Saudi Diabetics. Journal of Diabetes Mellitus. 2014; 225-231.

[15] Flatz A, Casillas A, Stringhini S. Association between education and quality of diabetes care in Switzerland. International Journal of General Medicine. 2015; 87-92. PMid:25759596 https: //doi.org/10.2147/IJGM.S77139

[16] Sima L, Hadi H, Alireza M, et al. Effect of Educational Program on Quality of Life of Patients with Heart Failure: A Randomized Clinical Trial. Journal of Caring Sciences. 2013; 2(1): 11-18. 